\title{
Relationship Between Electrodiagnosis and Various Ultrasonographic Findings for Diagnosis of Carpal Tunnel Syndrome
}

\author{
Kyoung Moo Lee, MD, Hyo Jong Kim, MD
}

Department of Rehabilitation Medicine, Chungbuk National University College of Medicine, Cheongju, Korea

\begin{abstract}
Objective To investigate the relationship between electrodiagnosis and various ultrasonographic findings of carpal tunnel syndrome (CTS) and propose the ultrasonographic standard that has closest consistency with the electrodiagnosis.

Methods Ultrasonography was performed on 50 female patients (65 cases) previously diagnosed with CTS and 20 normal female volunteers (40 cases). Ultrasonography parameters were as follows: cross-sectional area (CSA) and flattening ratio (FR) of the median nerve at the levels of hamate bone, pisiform bone, and lunate bone; anteroposterior diameter (AP diameter) of the median nerve in the carpal tunnel; wrist to forearm ratio (WFR) of median nerve area at the distal wrist crease and $12 \mathrm{~cm}$ proximal to distal wrist crease; and compression ratio (CR) of the median nerve. Independent t-test was performed to compare the ultrasonographic findings between patient and control groups. Significant ultrasonographic findings were compared with the electrodiagnosis results and a kappa coefficient was used to determine the correlation.

Results CSA and FR of median nerve at the hamate bone level, CSA of median nerve at pisiform bone level, AP diameter of median nerve within the carpal tunnel, CSA of median nerve at the distal wrist crease and WFR showed significant differences between patient and control groups. WFR showed highest concordance with electrodiagnosis $(\kappa=0.71, \mathrm{p}<0.001)$.

Conclusion These findings suggested the applicability of ultrasonography, especially WFR, as a useful adjunctive tool for diagnosis of CTS.
\end{abstract}

Keywords Carpal tunnel syndrome, Diagnosis, Electrodiagnosis, Median nerve, Ultrasonography

Received July 30, 2015; Accepted October 26, 2015

Corresponding author: Hyo Jong Kim

Department of Rehabilitation Medicine, Chungbuk National University Hospital, 776 1(il)sunhwan-ro, Heungdeok-gu, Cheongju 28644, Korea. Tel: +82-43-269-6227, Fax: +82-43-269-6228, E-mail: hippocrates@hanmail.net

ORCID: Kyoung Moo Lee (http://orcid.org/0000-0002-3191-8848); Hyo-Jong Kim (http://orcid.org/0000-0001-8460-2698).

(c) This is an open-access article distributed under the terms of the Creative Commons Attribution Non-Commercial License (http://creativecommons.org/ licenses/by-nc/4.0) which permits unrestricted noncommercial use, distribution, and reproduction in any medium, provided the original work is properly cited. Copyright $\odot 2016$ by Korean Academy of Rehabilitation Medicine 


\section{INTRODUCTION}

Carpal tunnel syndrome (CTS) is the most common and widely known of the peripheral entrapment neuropathies. Diagnosis of CTS is mainly based upon clinical symptoms, physical examination and electrodiagnostic studies [1-3]. Recently, ultrasonography has become increasingly recognized as a valuable non-invasive, realtime diagnostic tool for CTS [4-6]. Ultrasonography is especially useful in detecting changes of soft tissue lesions, as well as the cause of median nerve compression by facilitating the visualization of surrounding organs $[4,7,8]$. In 1992, Buchberger et al. [6] first proposed the cutoff value of cross-sectional area (CSA) of median nerve at the pisiform bone level as the ultrasonographybased diagnostic criteria for CTS; however, later studies indicated inconsistencies of this diagnostic criteria [911]. Others proposed the flattening ratio (FR), wrist to forearm ratio (WFR) and CSA of median nerve at the hamate bone level for ultrasonographic diagnosis of CTS [5,6,12-14]. In Korea, the cutoff value for CSA of median nerve at the pisiform bone level was proposed for adults [11]. CTS is possibly correlated with FR of median nerve at the pisiform bone level, compression ratio (CR) of median nerve at the pisiform bone level and lunate bone level and anteroposterior diameter (AP diameter) of median nerve in the carpal tunnel $[7,15]$. In addition, the CSA of median nerve at the lunate bone level is a useful prognostic marker of carpal tunnel release [16]. Ultrasonography as the initial examination prior to performing electrodiagnosis is proposed based on earlier studies on ultrasonographic-diagnosis of CTS [10,13]; however, selection of the most appropriate ultrasonographic finding for diagnosis of CTS remains a challenge.

In this study, we investigated the relationship between the ultrasonography and electrodiagnosis based on previously reported ultrasonographic findings. In addition, we determined ultrasonographic-diagnostic standards for CTS that were most consistent with electrodiagnostic findings.

\section{MATERIALS AND METHODS}

\section{Subject}

Female patients with confirmed CTS by electrodiagnosis were selected from patients referred to the rehabilita- tion center for suspected CTS from July 2014 to June 2015. Patients with history of trauma or surgery of the wrist area or diabetes were excluded from the study. A total of 50 female patients (65 cases) were assigned to the experimental group; whereas, 20 normal female volunteers ( 40 cases) without evidence of CTS based on clinical symptoms and electrodiagnosis were assigned to the control group.

\section{Method}

\section{Measurement of wrist circumference and BMI}

The experimental and control groups were compared by age, wrist circumference, forearm circumference and body mass index (BMI), in order to exclude the physical effects of the two groups. The wrist circumference was measured at the distal wrist crease area. The forearm circumference was measured at $12 \mathrm{~cm}$ proximal to the distal wrist crease area.

\section{Electrodiagnostic test}

A Medelec Synergy system (Oxford Instruments, Oxford, UK) was used for electrodiagnostic test. The indoor temperature was maintained at $25^{\circ} \mathrm{C}-28^{\circ} \mathrm{C}$. The antidromic technique was used for the electrodiagnostic test of median nerve. For motor nerve conduction of median nerve, the active electrode was attached in the middle of abductor pollicis brevis, the reference electrode was attached on the lateral part of interphalangeal joint of the thumb, and the ground electrode was attached between the stimulus site and active electrode. The stimulus site was $8 \mathrm{~cm}$ proximal to active electrode on the median motor nerve $[17,18]$. For the sensory nerve conduction of median nerve, the active electrode was attached on the proximal interphalangeal joint of second finger, whereas the reference electrode was attached $4 \mathrm{~cm}$ distal to the active electrode. The ground electrode was attached between the stimulus site and active electrode. The median sensory nerve was stimulated at $14 \mathrm{~cm}$ proximal to active electrode $[17,18]$. As proposed by Johnson et al. [19], the active electrode was attached on the sensory area of median nerve and ulnar nerve on the proximal interphalangeal joint of the 4th finger, and $14 \mathrm{~cm}$ proximal; the median nerve and ulnar nerve were stimulated to compare the onset latency. The diagnostic standard for CTS was based on the American Association of Neuromuscular and Electrodiagnostic Medicine (AANEM) recommendations [20]. 

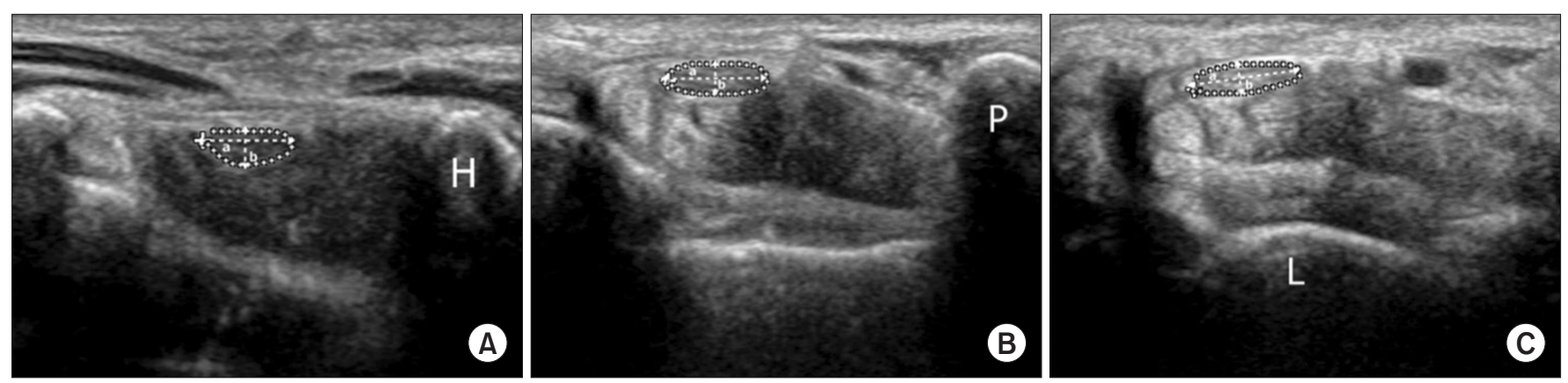

Fig. 1. Transverse sonogram of the median nerve at three different levels in a normal subject. The cross-sectional area of the median nerve (oval dotted line). Flattening ratio was obtained by measuring transverse (a) and anteroposterior (b) diameters. (A) Hamate bone (H) level. (B) Pisiform bone (P) level. (C) Lunate bone (L) level.

\section{Ultrasonography}

The 5-17 MHz probe of iU22 (Philips, Bothell, WA, USA) was used for ultrasonography. Wrist was maintained neutral at the position of palm toward the top from the supine position. The inspector was blinded to the results of electrodiagnosis. Another inspector performed the ultrasonography on 15 patients to obtain the inter-rater reliability. Ultrasonography was performed as follows. First, the CSA and FR of median nerve were obtained at the levels of the hamate bone, pisiform bone and lunate bone. CSA was measured by the continuous trace method that mechanically follows the internal boundary of nerve sheath of high density near the median nerve of low density. The FR was measured as the ratio $(a / b)$ of major axis (a) to the minor axis (b) (Fig. 1). Second, the thickest AP diameter including the median nerve and nerve sheath was measured at the position of probe parallel to the median nerve in the carpal tunnel (Fig. 2). Third, the WFR of median nerve was obtained from the distal wrist crease and at $12 \mathrm{~cm}$ proximal and expressed as a ratio of the CSA of median nerve at the two sites (Fig. 3). Lastly, the CR of median nerve was obtained. The CR of median nerve was considered the ratio of the FR of median nerve at the lunate bone level to the FR of median nerve at the pisiform bone level.

\section{Statistical analysis}

The physical measurements and ultrasonographic measurements were obtained from both experimental and control groups. The independent t-test was performed to verify a statistical significance in both groups. The statistical results were presented by mean \pm standard deviation, and the $\mathrm{p}$-value $<0.05$ was considered as statistical

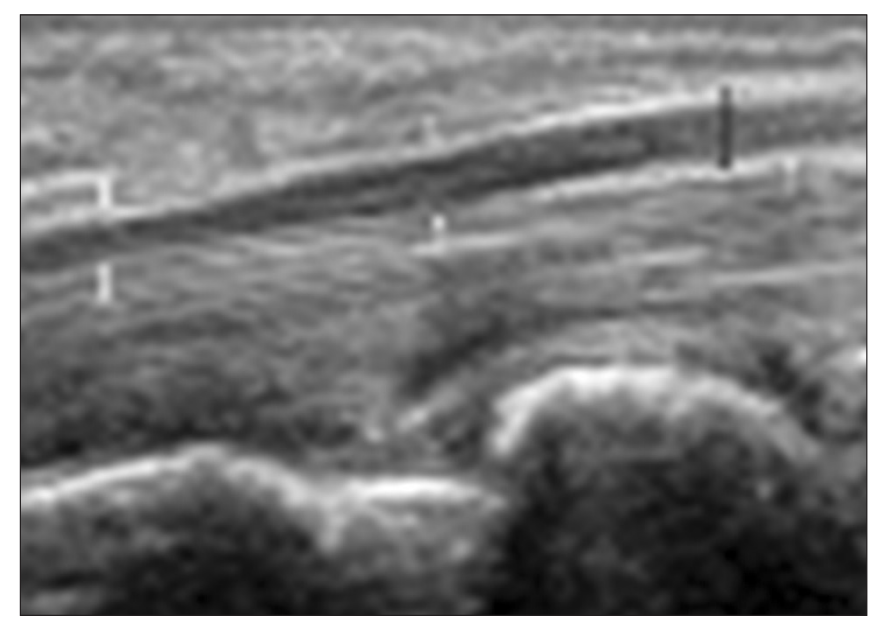

Fig. 2. Longitudinal sonogram of the median nerve (between white arrows) at the level of the carpal tunnel in a normal subject. The thickest anteroposterior diameter of the median nerve (black arrow).

significance. The consistency between significant ultrasonographic findings and electrodiagnosis in the experimental group was determined based on the kappa coefficient. However, the cutoff value for the AP diameter of median nerve in the carpal tunnel has not been proposed in previous studies. Instead, the CSA of the median nerve at the distal wrist crease is considered while obtaining the WFR, and is therefore excluded from the comparison with electrodiagnosis. Previous studies have shown varying results for the FR at the hamate bone level and cutoff value of CSA of median nerve at the pisiform bone level. Therefore, the FR at the hamate bone level was divided into 3.4 and 4.2; whereas, the CSA of median nerve at the pisiform bone level was divided into $8.5 \mathrm{~mm}^{2}, 9.0 \mathrm{~mm}^{2}$, $10.7 \mathrm{~mm}^{2}$ and $15.0 \mathrm{~mm}^{2}$. The inter-reader reliability of ultra- 

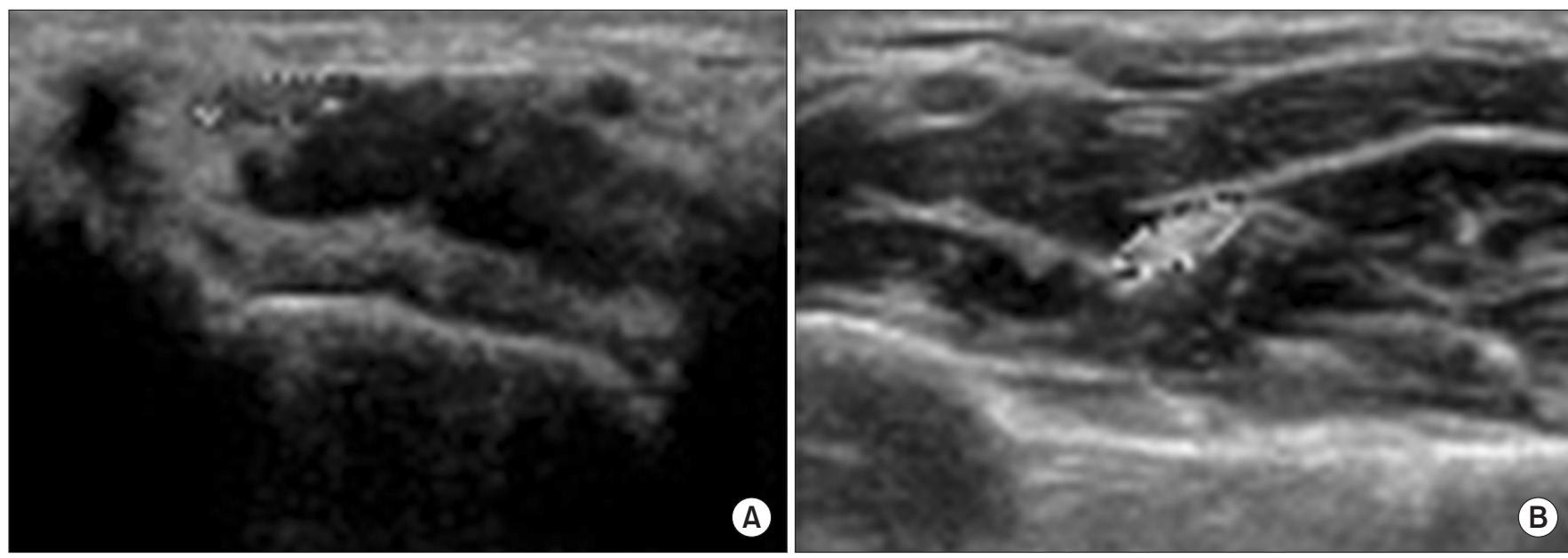

Fig. 3. Transverse sonogram of the median nerve with cross-sectional area (within oval dotted line) in a normal subject. (A) At the distal wrist crease. (B) At $12 \mathrm{~cm}$ proximal in the forearm. The wrist to forearm ratio was calculated as the ratio of the median nerve area at the distal wrist crease as compared to the forearm.

Table 1. Characteristics of subjects

\begin{tabular}{|ccc|}
\hline Characteristic & $\begin{array}{c}\text { Experimental } \\
\text { group } \\
(\mathbf{n}=\mathbf{5 0})\end{array}$ & $\begin{array}{c}\text { Control } \\
\text { group } \\
(\mathbf{n}=\mathbf{2 0})\end{array}$ \\
\hline Age (yr) & $46.2 \pm 13.4$ & $44.2 \pm 14.8$ \\
$\begin{array}{c}\text { Body mass index } \\
\left(\mathrm{kg} / \mathrm{m}^{2}\right)\end{array}$ & $20.9 \pm 2.5$ & $20.7 \pm 1.7$ \\
\hline $\begin{array}{c}\text { Circumference of } \\
\text { wrist }(\mathrm{cm})\end{array}$ & $14.8 \pm 1.6$ & $14.6 \pm 1.1$ \\
\hline $\begin{array}{c}\text { Circumference of } \\
\text { forearm }(\mathrm{cm})\end{array}$ & $20.4 \pm 1.6$ & $20.1 \pm 2.2$ \\
\hline $\begin{array}{c}\text { Occupation } \\
\text { Unemployed }\end{array}$ & 6 & 3 \\
\hline Housewife & 18 & 7 \\
\hline Office worker & 11 & 4 \\
\hline Manual labor & 15 & 6 \\
\hline Dominant hand & & \\
\hline Right & 49 & 20 \\
\hline Left & 1 & 0 \\
\hline Lesion hand & & \\
\hline Right & 31 & 0 \\
\hline Left & 4 & 0 \\
\hline Both & 15 & \\
\hline
\end{tabular}

Values are presented as mean \pm standard deviation or number.

sonography was calculated using the intraclass correlation coefficient (ICC). The SAS ver. 9.3 program (SAS Institute Inc., Cary, NC, USA) was used to calculate all statistics.
Table 2. Literature findings with diagnostic values for carpal tunnel syndrome

\begin{tabular}{cll}
\hline Ref. & Ultrasonographic measurement & $\begin{array}{c}\text { Cutoff } \\
\text { value }\end{array}$ \\
\hline$[13]$ & CSA at hamate bone $\left(\mathrm{mm}^{2}\right)$ & $>12.0$ \\
{$[14]$} & FR at hamate bone & $\geq 3.4$ \\
\hline$[10]$ & CSA at pisiform bone $\left(\mathrm{mm}^{2}\right)$ & $>15.0$ \\
\hline$[6]$ & CSA at pisiform bone $\left(\mathrm{mm}^{2}\right)$ & $>10.7$ \\
\hline & FR at hamate bone & $\geq 4.2$ \\
\hline 9$]$ & CSA at pisiform bone $\left(\mathrm{mm}^{2}\right)$ & $>9.0$ \\
\hline & FR at pisiform bone & $>3.3$ \\
\hline 11$]$ & CSA at pisiform bone $\left(\mathrm{mm}^{2}\right)$ & $\geq 8.5$ \\
\hline 15$]$ & AP diameter $(\mathrm{mm})$ & - \\
\hline$[12]$ & WFR & $\geq 1.4$ \\
\hline$[7]$ & CR & - \\
\hline
\end{tabular}

CTS, carpal tunnel syndrome; CSA, cross-sectional area; FR, flattening ratio; AP diameter, anteroposterior diameter of median nerve at carpal tunnel; WFR, wrist to forearm ratio of median nerve area; $\mathrm{CR}$, compression ratio between flattening ratio of median nerve at lunate bone level and pisiform bone level.

\section{RESULTS}

The independent t-test was performed for differences in the age, height, weight and BMI among patient and control groups. The results indicated no significant group wise differences in physical characteristics of the study subjects (Table 1). The electrodiagnostic test re- 
sult showed no evidence for CTS among the 20 subjects (40 cases) in the control group; whereas, 50 patents (65 cases) in the experimental group were diagnosed with CTS. Ultrasonography was performed on the patient and control groups as described in previous studies (Table 2). The results of ultrasonographic findings from the two groups were compared by independent t-test. A significant difference was found in both wrists of the experimental group, particularly the CSA and FR of median nerve at the hamate bone level, CSA of median nerve at the pisiform bone level, AP diameter of median nerve in the carpal tunnel, and CSA and WFR of median nerve in the distal wrist crease (Table 3). The consistency between ultrasonographic findings and electrodiagnostic test excluding the AP diameter of median nerve in the carpal tunnel and CSA of median nerve in the distal wrist crease showed statistical significance excluding the CSA cutoff value $\left(15.0 \mathrm{~mm}^{2}\right)$ of median nerve at the pisiform bone level. The WFR showed a kappa coefficient of 0.71 $(\mathrm{p} \leq 0.05)$, indicating highest consistency with electrodiagnostic test; in addition, ICC for reliability between the inspectors was highest among all ultrasonographic findings (Table 4).

\section{DISCUSSION}

Carpal tunnel refers to the path comprising bones and ligaments between the carpal tunnel inlet and car-

Table 3. Ultrasonographic measurements in patient and control groups

\begin{tabular}{|c|c|c|c|c|}
\hline Variable & Side & Patient group & Control group & p-value \\
\hline Number of median nerve & & 65 & 40 & \\
\hline \multirow[t]{2}{*}{ CSA at hamate bone $\left(\mathrm{mm}^{2}\right)$} & Right & $12.2 \pm 1.8$ & $7.1 \pm 1.2$ & $<0.001^{*}$ \\
\hline & Left & $11.7 \pm 1.3$ & $7.0 \pm 1.3$ & $<0.001^{*}$ \\
\hline \multirow[t]{2}{*}{ FR at hamate bone } & Right & $3.2 \pm 0.4$ & $2.8 \pm 0.4$ & $<0.001^{*}$ \\
\hline & Left & $3.1 \pm 0.4$ & $2.7 \pm 0.4$ & $0.004^{*}$ \\
\hline \multirow[t]{2}{*}{ CSA at pisiform bone $\left(\mathrm{mm}^{2}\right)$} & Right & $10.9 \pm 2.3$ & $7.1 \pm 1.4$ & $<0.001^{*}$ \\
\hline & Left & $11.3 \pm 2.2$ & $6.9 \pm 1.3$ & $<0.001^{*}$ \\
\hline \multirow[t]{2}{*}{ FR at pisiform bone } & Right & $3.0 \pm 0.8$ & $2.8 \pm 0.4$ & 0.167 \\
\hline & Left & $3.0 \pm 0.7$ & $2.7 \pm 0.4$ & 0.372 \\
\hline \multirow[t]{2}{*}{ CSA at lunate bone $\left(\mathrm{mm}^{2}\right)$} & Right & $7.7 \pm 2.7$ & $6.5 \pm 1.4$ & 0.097 \\
\hline & Left & $8.0 \pm 3.3$ & $6.5 \pm 1.7$ & 0.172 \\
\hline \multirow[t]{2}{*}{ FR at lunate bone } & Right & $2.7 \pm 0.5$ & $2.7 \pm 0.4$ & 0.609 \\
\hline & Left & $2.9 \pm 0.5$ & $2.6 \pm 0.4$ & 0.173 \\
\hline \multirow[t]{2}{*}{ AP diameter $(\mathrm{mm})$} & Right & $2.3 \pm 0.3$ & $1.7 \pm 0.4$ & $<0.001^{*}$ \\
\hline & Left & $2.3 \pm 0.6$ & $1.7 \pm 0.4$ & $0.001^{*}$ \\
\hline \multirow[t]{2}{*}{ CSA at distal wrist crease $\left(\mathrm{mm}^{2}\right)$} & Right & $12.5 \pm 2.2$ & $6.6 \pm 0.8$ & $<0.001^{*}$ \\
\hline & Left & $11.7 \pm 2.4$ & $6.9 \pm 1.1$ & $<0.001^{*}$ \\
\hline \multirow[t]{2}{*}{ CSA at forearm $\left(\mathrm{mm}^{2}\right)$} & Right & $6.3 \pm 0.8$ & $6.3 \pm 1.1$ & 0.766 \\
\hline & Left & $6.7 \pm 0.9$ & $6.2 \pm 1.1$ & 0.087 \\
\hline \multirow[t]{2}{*}{ WFR } & Right & $1.9 \pm 0.5$ & $1.1 \pm 0.2$ & $<0.001^{*}$ \\
\hline & Left & $1.9 \pm 0.5$ & $1.1 \pm 0.2$ & $<0.001^{*}$ \\
\hline \multirow[t]{2}{*}{ CR } & Right & $1.2 \pm 0.6$ & $1.0 \pm 0.3$ & 0.263 \\
\hline & Left & $1.1 \pm 0.2$ & $1.1 \pm 0.3$ & 0.620 \\
\hline
\end{tabular}

Values are presented as mean \pm standard deviation.

CSA, cross-sectional area; FR, flattening ratio; AP diameter, anteroposterior diameter of median nerve at carpal tunnel; WFR, wrist to forearm ratio of median nerve area; $\mathrm{CR}$, compression ratio between flattening of median nerve at lunate bone level and pisiform bone level.

${ }^{*} \mathrm{p} \leq 0.05$, statistically significant. 
Table 4. Concordance between electrodiagnosis and ultrasonography

\begin{tabular}{cccc}
\hline \multicolumn{1}{c}{ Variable } & $\begin{array}{c}\text { Cutoff } \\
\text { value }\end{array}$ & $\begin{array}{c}\text { Kappa } \\
\text { coefficient }\end{array}$ & ICC \\
\hline $\begin{array}{c}\text { CSA at hamate bone } \\
\left(\mathrm{mm}^{2}\right)\end{array}$ & $>12.0$ & $0.55^{*}$ & $0.839^{*}$ \\
FR at hamate bone & $\geq 4.2$ & $0.38^{*}$ & $0.860^{*}$ \\
& $\geq 3.4$ & $0.42^{*}$ & $0.843^{*}$ \\
$\begin{array}{c}\text { CSA at pisiform bone } \\
\left(\mathrm{mm}^{2}\right)\end{array}$ & $\geq 8.5$ & $0.64^{*}$ & $0.847^{*}$ \\
& $>9.0$ & $0.60^{*}$ & $0.850^{*}$ \\
& $>10.7$ & $0.51^{*}$ & $0.872^{*}$ \\
& $>15.0$ & 0.24 & $0.830^{*}$ \\
\hline WFR & $\geq 1.4$ & $0.71^{*}$ & $0.850^{*}$ \\
\hline
\end{tabular}

CTS, carpal tunnel syndrome; ICC, intraclass correlation coefficient; CSA, cross-sectional area; FR, flattening ratio; WFR, wrist to forearm ratio of median nerve area. ${ }^{*} \mathrm{p} \leq 0.05$, statistically significant.

pal tunnel outlet. Neurological symptoms were mainly caused by the compression of median nerve due to narrow path or increased internal pressure by various factors [16]. Compression of the median nerve causes neurological swelling, also referred to as epineurium edema from hemodynamic disorder [21,22]. Buchberger and his colleagues $[5,6]$ reported that neurologic swelling of median nerve is caused in the proximal area compression of carpal tunnel. They described three different ultrasonographic findings including thinned and flattened median nerve in the compression of distal carpal tunnel with the increased palmar bowing of retinaculum; in addition, CSA cutoff value $\left(10.7 \mathrm{~mm}^{2}\right)$ of the median nerve at the pisiform bone level was proposed as the ultrasonographic-diagnostic standard for CTS [6]. However, Duncan et al. [9] proposed $9 \mathrm{~mm}^{2}$ as the cutoff value of CSA of the median nerve at the pisiform bone level; while Lee et al. [10] proposed $15 \mathrm{~mm}^{2}$, and Park et al. [11] proposed 8.5 $\mathrm{mm}^{2}$ in Korean patients, suggesting inconsistencies in the ultrasonographic-diagnostic standard for CTS. Moreover, the increased CSA and FR of median nerve at the hamate bone level, or increasing WFR of median nerve were reported as suspected CTS $[6,9,12,13]$.

Choi et al. [7] did not propose the cutoff value but instead, showed a significant increase in the CR of median nerve between the distal and proximal carpal tunnel in the patients with CTS. Kim and Lee [15] reported a posi- tive correlation between CTS and increased AP diameter of median nerve in the carpal tunnel. Thus, it is difficult to determine the common standard for CTS patients since the ultrasonographic findings of CTS are varied, and patients with confirmed CTS do not satisfy all ultrasonographic findings.

In this study, we investigated the correlation between electrodiagnosis and ultrasonography. Due to various reported cutoff values of CSA in the median nerve at the pisiform bone level, the standard was divided into 8.5 $\mathrm{mm}^{2}, 9 \mathrm{~mm}^{2}, 10.7 \mathrm{~mm}^{2}$, and $15 \mathrm{~mm}^{2}$ and comparison purposes [6,9-11]. The criteria for FR of median nerve at the hamate bone level were divided into 4.2 and 3.4 based on previous studies $[6,14]$. On the other hand, the ultrasonographic-diagnostic value for the palmar bowing of flexor retinaculum is reportedly lower than MRI [6], which was excluded from this study. The subjects' age, BMI, wrist and forearm circumference were measured, in order to investigate the correlation of median nerve sizes; however, physical characteristics showed no significant difference in experimental and control groups. However, the CSA and FR of median nerve at the hamate bone level, CSA of median nerve at the pisiform bone level, AP diameter of median nerve in the carpal tunnel, CSA of median nerve in the distal wrist crease and WFR showed significant increase in the experimental group. Therefore, the abovementioned ultrasonographic findings were considered as the ultrasonographic-diagnostic standard for CTS. Since cutoff value of AP diameter was not proposed by Kim and Lee [15], it was difficult to compare with the electrodiagnosis in this study. The CSA of median nerve in the distal wrist crease was considered for estimation of the WFR; therefore, it was excluded from comparison with the electrodiagnosis. Excluding the AP diameter and the CSA of median nerve at the distal wrist crease, the highest consistency with the electrodiagnosis using the kappa coefficient was shown with WFR and CSA at the pisiform bone level (cutoff value $\geq 8.5 \mathrm{~mm}^{2}$ ), followed by the CSA at pisiform bone level (cutoff value $>9.0 \mathrm{~mm}^{2}$ ), CSA at hamate bone, CSA at pisiform bone level (cutoff value $>10.7 \mathrm{~mm}^{2}$ ), FR at hamate bone (cutoff value $\geq 3.4$ ), $F R$ at hamate bone (cutoff value $\geq 4.2$ ) and CSA at pisiform bone level (cutoff value $>15.0 \mathrm{~mm}^{2}$ ), in order. Thus, the WFR findings showed the highest consistency with the electrodiagnosis as a confirmatory test for CTS. Therefore, WFR findings had highest diagnostic 
value, according to previous reports on ultrasonographic findings. The kappa coefficient of WFR finding was 0.71, which was lower than the reported 0.8 standard. Based on these results, ultrasonography was considered a useful secondary diagnostic tool for CTS but not appropriate to replace the electrodiagnosis. However, ultrasonography has many diagnostic advantages for initial examination of CTS $[1,4-8,10,13]$.

In the current study, the difference in the FR of median nerve at the pisiform bone level was not significant between the experimental and control groups, unlike the study by Duncan et al. [9]. The area of median nerve in the normal patient is almost the same between the wrist and forearm [23]; however, due to swelling of the median nerve of wrist in CTS patients, the WFR ultimately increases [12]. WFR is based on the ratio, and is less affected by physical characteristics such as gender, weight, etc., as compared to the CSA of median nerve [12]. We observed a significant increase in the CSA of median nerve at the distal wrist crease in the experimental group; however, the difference at the forearm was not significant, as compared to the control group, in agreement with Hobson-Webb et al. [12]. Various cutoff values have been reported for the CSA of median nerve at the pisiform bone level; however, $8.5 \mathrm{~mm}^{2}$ showed the highest consistency with electrodiagnosis, corroborating the results reported by Park et al. [11] in Koreans. Most CTS patients did not remember the exact onset time of symptoms; therefore, no correlation was found between the duration of illness and ultrasonographic findings. In addition, several limitations of this study were as follows: (1) less number of subjects included; (2) unavailability of ultrasonographicdiagnostic standards for Korean people; and (3) in applicability of the study results to males, since only females were included as subjects. This study was performed prior to the surgical operation; therefore, a correlation study with the CSA at the lunate bone level including the postoperative follow-up test is required. In addition, a study on the consistency of ultrasonographic findings based on the severity of electrodiagnosis is necessary. In this study, the ultrasonographic-WFR measurement showed the highest consistency with the electrodiagnostic results in the ultrasonography of CTS. The CSA of median nerve by ultrasonography also showed a significant result, however, the cutoff value varies with physical differences of subjects. In ultrasonography of CTS, WFR that was less affected by subjects' physical factors showed the highest consistency with the electrodiagnosis.

\section{CONFLICT OF INTEREST}

No potential conflict of interest relevant to this article was reported.

\section{REFERENCES}

1. Phalen GS. The carpal-tunnel syndrome: clinical evaluation of 598 hands. Clin Orthop Relat Res 1972;83:2940.

2. El Miedany Y, Ashour S, Youssef S, Mehanna A, Meky FA. Clinical diagnosis of carpal tunnel syndrome: old tests-new concepts. Joint Bone Spine 2008;75:451-7.

3. Jablecki CK, Andary MT, Floeter MK, Miller RG, Quartly CA, Vennix MJ, et al. Practice parameter: Electrodiagnostic studies in carpal tunnel syndrome. Report of the American Association of Electrodiagnostic Medicine, American Academy of Neurology, and the American Academy of Physical Medicine and Rehabilitation. Neurology 2002;58:1589-92.

4. Buchberger W. Radiologic imaging of the carpal tunnel. Eur J Radiol 1997;25:112-7.

5. Buchberger W, Schon G, Strasser K, Jungwirth W. High-resolution ultrasonography of the carpal tunnel. J Ultrasound Med 1991;10:531-7.

6. Buchberger W, Judmaier W, Birbamer G, Lener M, Schmidauer C. Carpal tunnel syndrome: diagnosis with high-resolution sonography. AJR Am J Roentgenol 1992;159:793-8.

7. Choi WK, Kang YK, Kim YH, Park EM. Diagnosis of carpal tunnel syndrome by diagnostic ultrasound. J Korean Acad Rehabil Med 2001;25:134-9.

8. Kim MS, Yoon SY, Lee SO, Lee YG. The abnormal ultrasonographic findings of carpal tunnel in carpal tunnel syndrome. J Korean Acad Rehabil Med 2003;27:735-9.

9. Duncan I, Sullivan P, Lomas F. Sonography in the diagnosis of carpal tunnel syndrome. AJR Am J Roentgenol 1999;173:681-4.

10. Lee D, van Holsbeeck MT, Janevski PK, Ganos DL, Ditmars DM, Darian VB. Diagnosis of carpal tunnel syndrome: ultrasound versus electromyography. Radiol Clin North Am 1999;37:859-72. 
11. Park GY, Bae JH, Lee SY, Oh JS, Lim JG, Son DG. Ultrasonographic findings of mild and very mild carpal tunnel syndrome. J Korean Acad Rehabil Med 2008;32:67-72.

12. Hobson-Webb LD, Massey JM, Juel VC, Sanders DB. The ultrasonographic wrist-to-forearm median nerve area ratio in carpal tunnel syndrome. Clin Neurophysiol 2008;119:1353-7.

13. Wong SM, Griffith JF, Hui AC, Lo SK, Fu M, Wong KS. Carpal tunnel syndrome: diagnostic usefulness of sonography. Radiology 2004;232:93-9.

14. Keberle M, Jenett M, Kenn W, Reiners K, Peter M, Haerten R, et al. Technical advances in ultrasound and MR imaging of carpal tunnel syndrome. Eur Radiol 2000;10:1043-50.

15. Kim HJ, Lee BN. Correlation of ultrasonography with the nerve conduction study in carpal tunnel syndrome of Koreans. J Korean Assoc EMG Electrodiagn Med 2006;8:21-5.

16. Lee SJ, Kim JS, Choi YR, Kim SJ, Kang HJ. Relationship between change of median nerve cross-sectional area measured by ultrasonography and prognosis after carpal tunnel release. J Korean Orthop Assoc 2013;48:290-6.

17. Johnson EW, Melvin JL. Sensory conduction studies of median and ulnar nerves. Arch Phys Med Rehabil 1967;48:25-30.

18. Melvin JL, Schuchmann JA, Lanese RR. Diagnostic specificity of motor and sensory nerve conduction variables in the carpal tunnel syndrome. Arch Phys Med Rehabil 1973;54:69-74.

19. Johnson EW, Kukla RD, Wongsam PE, Piedmont A. Sensory latencies to the ring finger: normal values and relation to carpal tunnel syndrome. Arch Phys Med Rehabil 1981;62:206-8.

20. American Association of Electrodiagnostic Medicine, American Academy of Neurology, and American Academy of Physical Medicine and Rehabilitation. Practice parameter for electrodiagnostic studies in carpal tunnel syndrome: summary statement. Muscle Nerve 2002;25:918-22.

21. Akelman E, Weiss AP. Carpal tunnel syndrome. Etiology and endoscopic treatment. Orthop Clin North Am 1995;26:769-78.

22. Omer GE Jr. Median nerve compression at the wrist. Hand Clin 1992;8:317-24.

23. Cartwright MS, Shin HW, Walker FO. Ultrasonographic characteristics of the normal median nerve. Neurology 2006;66(Suppl 2):A83. 